\title{
Shock Wave Attenuation Characteristics of Aluminum Foam Sandwich Panels Subjected to Blast Loading
}

\author{
Jinglin Xu $\left(\mathbb{D}\right.$, Jianqing Liu $\mathbb{D}^{D}$, Wenbin Gu $\mathbb{D}^{\mathbb{D}}$, Xin Liu $(\mathbb{D}$, and Tao Cao \\ PLA Army Engineering University, Nanjing, China \\ Correspondence should be addressed to Jianqing Liu; qq5893736@163.com
}

Received 11 January 2018; Accepted 1 April 2018; Published 7 May 2018

Academic Editor: Lorenzo Dozio

Copyright ( 2018 Jinglin Xu et al. This is an open access article distributed under the Creative Commons Attribution License, which permits unrestricted use, distribution, and reproduction in any medium, provided the original work is properly cited.

\begin{abstract}
Comparative experiments were conducted with two different structures to study the mechanism of aluminum foam sandwich attenuating blast shock wave. The sandwich structure is composed of "steel-aluminum foam-steel," and the mild steel structure is composed of "steel-steel." In the experiment, the polyvinylidene fluoride transducers were used to directly test the load of stress wave between different interfaces of sandwich and mild steel structures. The strain of back sheet was simultaneously measured using high-precision strain gauge. The accuracy of the test results was verified by Henrych's formula. Experimental results show that the wave attenuation rate on the mild steel structure is only $11.3 \%$, whereas the wave attenuation rate on the sandwich structure can exceed $90 \%$. The interface effect is clearly a more crucial factor in the wave attenuation. The peak value of back sheet strain in the mild steel structure is much higher than the sandwich structure. The apparent overall " $\mathrm{X}$ " crushing band is produced in the aluminum foam core, and scanning electron microscope (SEM) observation clearly shows the collapse of the cell wall. Experiments on the sandwich structure with different aluminum foam densities indicate that increasing the relative density results in increased attenuation capability of the aluminum foam and decreased attenuation capability of the sandwich structure. Experiments on the sandwich structure with different aluminum foam thickness indicate that increasing the thickness results in increased attenuation capability of the aluminum foam and the sandwich structure.
\end{abstract}

\section{Introduction}

Aluminum foam (ALF) is porous material that consists of thousands of random three-dimensional polyhedral pores embedded in a continuous aluminum or aluminum alloy matrix. ALF is divided into closed-cell and open-cell structures depending on the properties of the internal pores. Compared with other composite materials, ALF has many excellent advantages such as light weight and high strength. It is widely used in aerospace and military applications, such as fuselage of space shuttle, armor of military tanks, and naval warship. In addition, the excellent thermal insulation and sound absorption properties of ALF make it popular in civil engineering $[1,2]$. Some novel ALF structures have been put forward in recent years with the development of material science. Researchers can diversify the mechanical properties of ALF by adding different matrix materials or additives, thereby making ALF very popular in scientific research and commercial application [3-7]. ALF has an almost constant plateau stress during compression because of its porous nature, making it very effective in shock wave attenuation and energy absorption and essential in the field of blast impact protection [8-12].

A typical sandwich structure is composed of two thin metallic face plates and a thick porous metal core in the middle. The face plates can be steel plates, aluminum plates, or fiber metal laminates, which mainly bear shock loads and bending moments. The core material can be metallic honeycomb and ALF, which mainly bear transverse shear loads $[13,14]$. Some theoretical research on dynamic response of sandwich structure under blast loading was proposed firstly. Qiu et al. [15] established a theoretical model of the circular sandwich panels under the condition of solid support. Because the action time of the explosive load, the compression response time of the core layer, and the whole dynamic response time of the sandwich structure differ in magnitude, the deformation of the sandwich panel structure is divided into three consecutive stages: (I) the fluid-solid 
coupling stage, (II) the core layer compression stage, and (III) the combined action of the sandwich panel bending and stretching stage. Deshpande and Fleck [16] established a onedimensional impact model of sandwich panel under pulsed load to determine the effect of the strain rate of ALF. Zhu et al. [17] conducted experiments based on the above theoretical model to verify the reliability of the analytical model and optimize the sandwich structures. Existing experimental research mainly focuses on the macroscopic dynamic response of the sandwich structures under blast loading. Langdon et al. [18] studied the different failure modes of sandwich panels under blast loading. Jing et al. $[19,20]$ studied the dynamic response of the cylindrical shell and observed various failure modes, such as indentation or tearing of the front face sheet and collapse of the core. Shen et al. [21] studied the effect of curvature radius on cylindrical sandwich shells. Li et al. [22] explored the dynamic response of the spherical shell and found that the spherical shell possesses better antiexplosive effect than the cylindrical shell. Liu et al. [23, 24] explored the effect of the functionally graded metallic foam on the sandwich structure.

The theoretical research on the stress wave attenuation effect of sandwich with ALF core mostly focuses on the establishment of a simplified one-dimensional model. Based on the R-P-P-L mode of ALF, Tan et al. [25] set up a onedimensional model of stress wave theory. Karagiozova et al. [26] established the theoretical model of blast shock wave traveling progress in Cymat ALF and studied the effects of double-layer ALF structure [27], continuous density ALF structure [28], and ALF structure with strain hardening effect [29] and derived theoretical solutions. Aleyaasin et al. [30] built the second-order nonlinear ordinary differential equations based on the conservation of momentum and the stress wave theory and calculated the degree of compression of ALF under different loading conditions. Turkyilmazoglu [31] derived analytical solutions based on the model of Aleyaasin. Liang et al. [32] established a one-dimensional theoretical model for the porous material with continuous density gradient variation, and their theoretical model was verified by the results of the finite element model established by the random Voronoi technique.

Few people have reported the experimental test results of the stress wave attenuation during the sandwich structure with ALF under blast loading. Goel et al. [33] investigated the interaction of closed-cell ALF with shock waves using a conventional shock tube. The presence or absence of the ALF core significantly affects the reflected wave. Liang et al. [34] used PVDF (polyvinylidene fluoride) transducers to test the stress wave propagation of sandwich structures under the high-speed impact load $(370 \mathrm{~m} / \mathrm{s})$, and the stress wave attenuation after the ALF foam was very clear. Liu et al. [35] investigated the performance of the sandwich structure with ALF core under blast loading. But, in his study, the interface stress between the steel plate and the ALF core was missing. In addition, the distance between the sandwich and the explosives was very close in his research. Thus, the sandwich structure was subjected to double loading of detonation gas products and shock waves, resulting in the coupling effect. This study focuses on the measurement of the interface stress

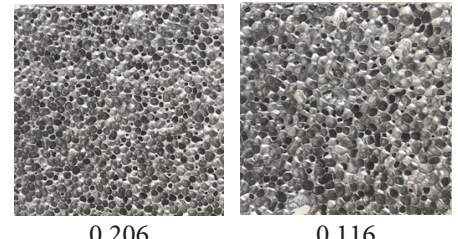

0.116

FIGURE 1: Images of aluminum foam with different relative densities.

between the steel and the ALF materials in the decoupled conditions when the entire sandwich structure was only subjected to the loading of the blast shock wave. The test results on stress wave propagation between different interfaces can explain the mechanism of stress wave attenuation in the sandwich structure.

\section{Experimental Methods}

2.1. Calibration of Polyvinylidene Fluoride Transducers. The polyvinylidene fluoride (PVDF) transducers are used to test the load of interface stress in the sandwich and mild steel structures. The dynamic sensitivity coefficient of the PVDF transducers should generally be calibrated before use in the explosive experiments. The Split Hopkinson Bar (SHPB), which could provide dynamic loading, is perfectly suited for dynamic calibration of PVDF sensors. The relationship between charge amount and pressure is linear for the PVDF sensors. PVDF transducers connect with the appropriate resistance, and the amount of charge can be determined by measuring the voltage of the resistor. The relationship between the stress $\sigma$ and the charge $Q$ can be expressed as follows:

$$
\begin{aligned}
\sigma(t) & =\frac{Q(t)}{A K}, \\
Q(t) & =\int_{0}^{t} \frac{U(t)}{R} d t,
\end{aligned}
$$

where $A$ is the effective area of PVDF transducers, $K$ is the dynamic sensitivity coefficient of the PVDF sensor, $U$ is the voltage obtained by the data acquisition instrument, and $R$ is the resistance. The PVDF sensor was placed between the incident bar and the transmission bar in the SHPB experiment. A series of pressure pulses could be obtained by adjusting the velocity of the striker, and the linear equation between charge amount and the pressure could then be established. The final dynamic sensitivity coefficient of PVDF film sensor is $78.5 \mathrm{PC} / \mathrm{N}$.

2.2. Materials. In the present work, ALPORAS closed-cell ALF was manufactured in liquid state using the blowing agent procedure with a chemical composition Al-1.5Ca-1.5Ti. The relative density of ALF is defined as the density of ALF and the matrix metal density. Two typical images of the experimental sample are shown in Figure 1. The relative densities of the first and second image are 0.206 and 0.116 , respectively. The face plate is made of A3 steel with yield strength of $235 \mathrm{MPa}$. 

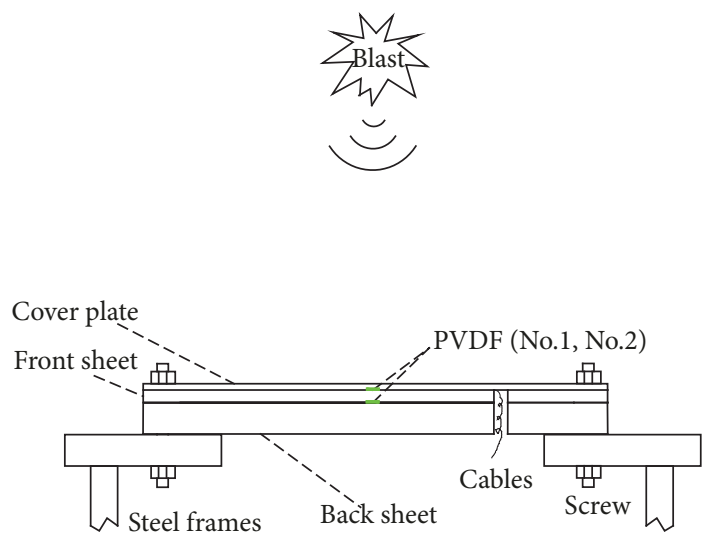

(a)
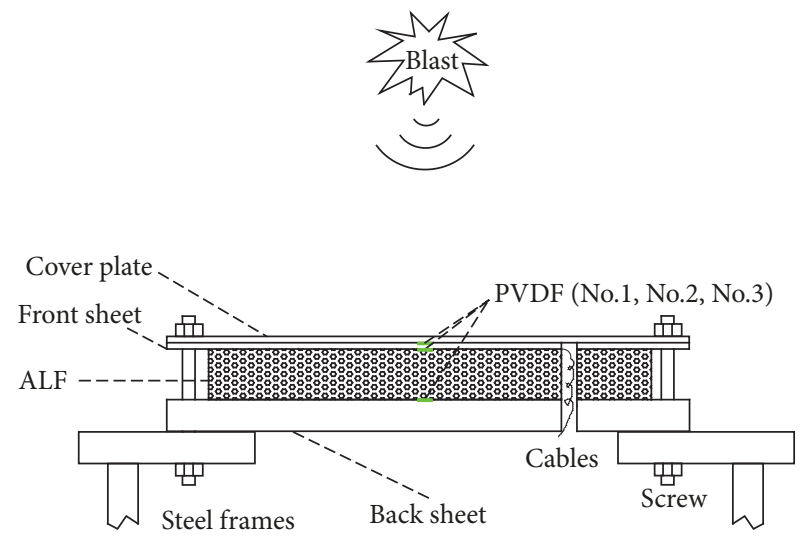

(b)
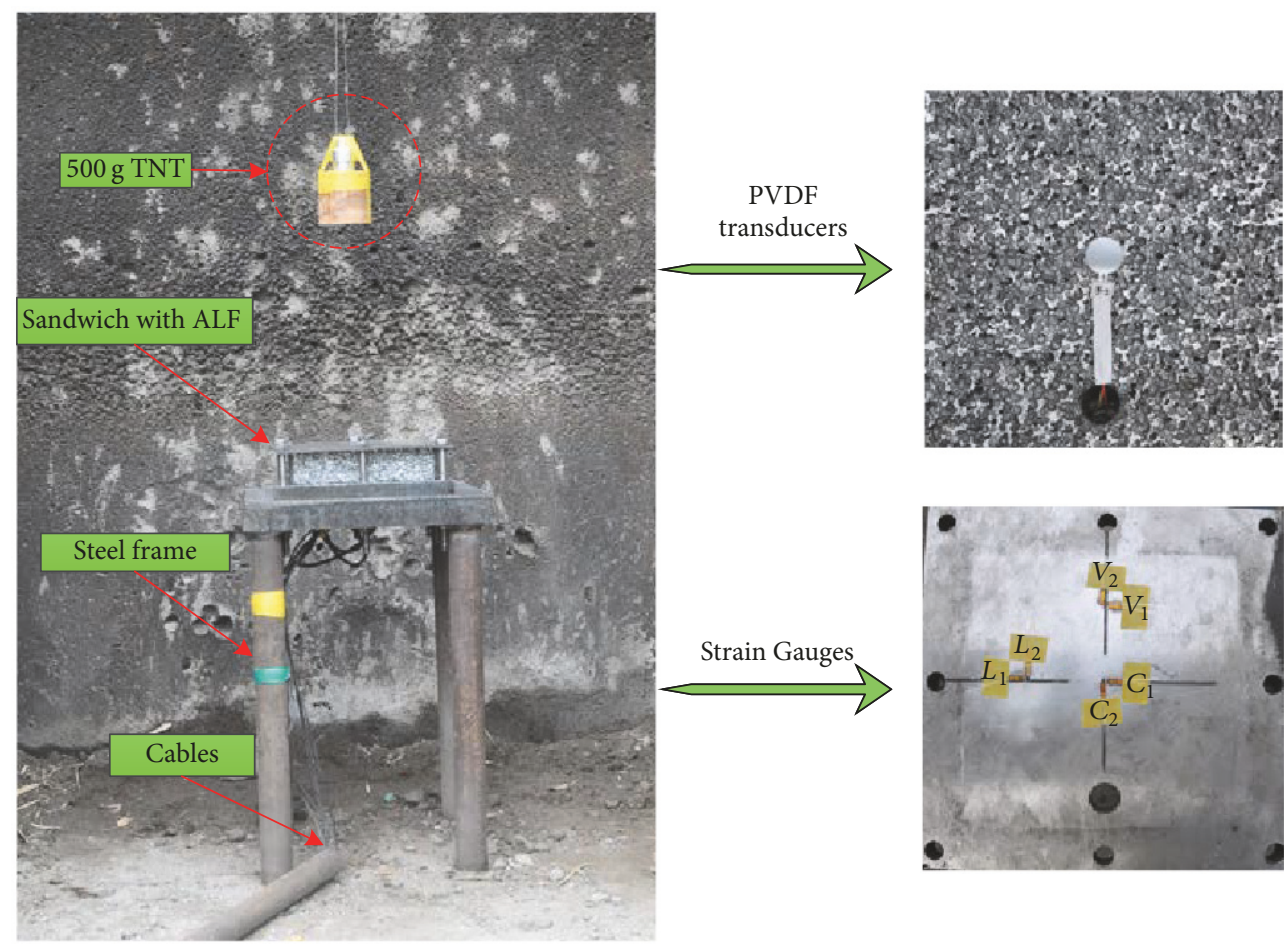

(c)

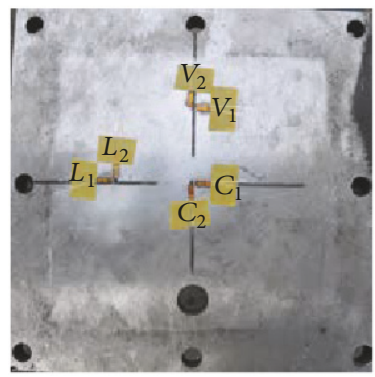

FIGURE 2: Experimental measurements of stress wave and strain: (a) mild steel structure, (b) aluminum foam sandwich structure, and (c) experimental devices.

2.3. Measurement of Stress Wave and Strain. After detonation, the explosives produced high temperature, pressure detonation gas products, and shock waves, which could cause serious damage to the surrounding structures. A 500-gram cylindrical TNT explosive was selected in each experiment. It was suspended at the center of the mild steel or sandwich structure at a distance of $320 \mathrm{~mm}$. As the detonation distance was almost 10 times the diameter of the TNT explosive, the front sheet of the structure could be deduced to be affected only by blast shock wave. The PVDF transducer was installed in the interfaces between different materials, as shown in Figure 2. The PVDF sensor can directly test the load of the stress wave. Figure 2(a) shows the installation location of
PVDF sensors in mild steel structure, in which the surface size of each steel plate was $250 \mathrm{~mm} \times 250 \mathrm{~mm}$. The thickness of first-layer steel plate, a protective cover plate of PVDF sensor, was $2 \mathrm{~mm}$. The second-layer steel plate, the front sheet of the mild steel structure, was $4.2 \mathrm{~mm}$ thick. The thirdlayer steel plate, the back sheet of the mild steel structure, was $20 \mathrm{~mm}$ thick. The entire mild steel structure was fixed on the steel frame with eight screws. A cylindrical hole was drilled in the front and back sheets to protect the electric cables. A total of two PVDF sensors were set in the mild steel structure. Figure 2(b) shows the installation location of PVDF sensors in the sandwich structure, in which the surface size of each steel plate was $250 \mathrm{~mm} \times 250 \mathrm{~mm}$, whereas the 


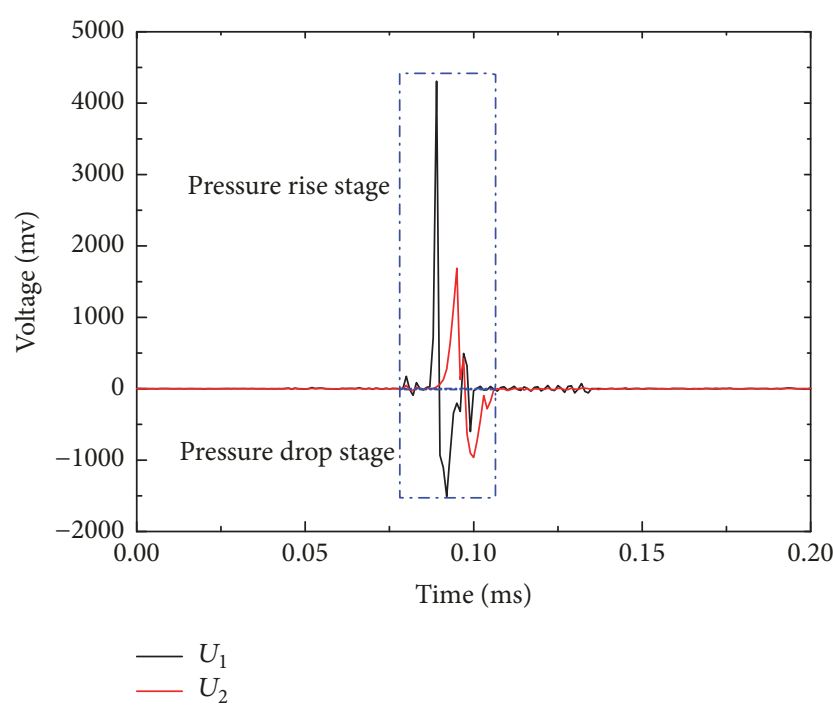

(a)

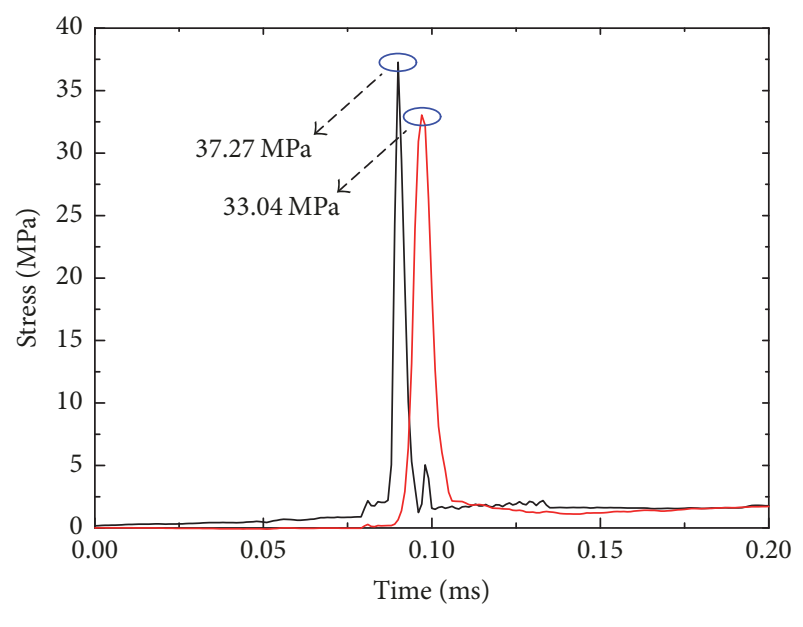

(b)

(b)

FIGURE 3: Measurement signal in the mild steel structure: (a) voltage signal; (b) stress signal.

surface size of ALF was $200 \mathrm{~mm} \times 200 \mathrm{~mm}$. The thickness of first-layer steel plate, a protective cover plate of PVDF sensor, was $2 \mathrm{~mm}$. The second-layer steel plate, the front sheet of the sandwich structure, was $2 \mathrm{~mm}$ thick. The third layer, ALF, was $48 \mathrm{~mm}$ thick. The fourth-layer steel plate, the back sheet of the sandwich structure, was $20 \mathrm{~mm}$ thick. The relative density of ALF core was $20.6 \%$, and the total mass of the sandwich structure was the same as the mild steel structure. A total of three PVDF sensors were set in the sandwich structure.

Three groups of rectangular strain rosettes were set on the surface of the back sheet, as shown in Figure 2(c). The different dynamic responses of the back sheet between mild steel and sandwich structures were measured by the highprecision strain gauge. The first group of the strain gauges was placed at the center point $(C)$ of the back sheet. The second and third groups of rectangular strain rosette were located at positions $50 \mathrm{~mm}$ away from the center of the back sheet in the vertical $(V)$ and horizontal $(L)$ directions.

\section{Results and Discussions}

3.1. Stress Wave Attenuation in the Mild Steel Structure. The typical signal recorded by the PVDF sensor in the mild steel structure under blast loading is shown in Figure 3. The voltage signal between the cover plate and the front sheet is recorded as $U_{1}$, and the voltage signal between the front and back sheets is recorded as $U_{2}$, whereas their stress wave signals are recorded as $\sigma_{1}$ and $\sigma_{2}$, respectively. Figure 3(a) shows the voltage signal recorded directly by the data acquisition instrument. The voltage signal does not directly represent the magnitude of the stress wave. It indicates the change rate of the stress wave. The positive and negative voltage signals signify the rising and falling trends, respectively, of the stress wave. The resistances connected to the PVDF, $R_{1,2}=5.29 \Omega$, the area of PVDF transducer, $A=3.14 \times 10^{-4} \mathrm{~m}^{2}$, and the dynamic sensitivity coefficient $K=78.5 \mathrm{PC} / \mathrm{N}$. So according to (1), the conversion factor between the magnitude of the stress and the voltage signal should be 0.1304 . Stress wave signal is acquired by integrating the voltage signal, as shown in Figure 3(b). The peak load of $\sigma_{1}$ is $37.27 \mathrm{MPa}$, whereas the peak load of $\sigma_{2}$ is $33.04 \mathrm{MPa}$. The stress wave attenuation coefficient $(\beta)$ of the structure is defined as

$$
\beta_{i-1}=\frac{\left(\sigma_{1}-\sigma_{i}\right)}{\sigma_{1}} .
$$

According to (2), the stress wave attenuation coefficient of mild steel structure is only $11.3 \%$. In addition, only one peak can be observed in the stress wave curves, indicating that the steel plate is only affected by the blast shock wave.

3.2. Stress Wave Attenuation in the Sandwich Structure. Figure 4 shows the measurement signal between different interfaces in the sandwich structure. $U_{1}$ represents the voltage signal between the cover plate and the front sheet. $U_{2}$ represents the voltage signal between the front sheet and the ALF core. $U_{3}$ represents the voltage signal between the ALF and the back sheet. $\sigma_{1}, \sigma_{2}$, and $\sigma_{3}$ represent the stress wave signals of $U_{1}, U_{2}$, and $U_{3}$, respectively. The resistances connected to the PVDF, $R_{1}=10.14 \Omega, R_{2}=10.60 \Omega$, and $R_{3}=35.61 \Omega$, so the conversion factor between the magnitude of the stress and the voltage signal should be $0.2499,0.2613$, and 0.8778 , respectively. Every stress wave signal has "double-peak" characteristics. The peak values of $\sigma_{1}, \sigma_{2}$, and $\sigma_{3}$ are $29.64,8.58$, and $2.41 \mathrm{MPa}$, respectively. The stress wave attenuation coefficients calculated by $\sigma_{1}$ and $\sigma_{3}$ reach $91.9 \%$ in the sandwich structure, which is much higher than that of the mild steel structure. The rising times of $\sigma_{1}$, $\sigma_{2}$, and $\sigma_{3}$ are 3,10 , and $41 \mu$ s, respectively, in their first cycle. The rising time of the stress wave has been greatly improved after passing through ALF material. As the rising times of $\sigma_{2}$ 


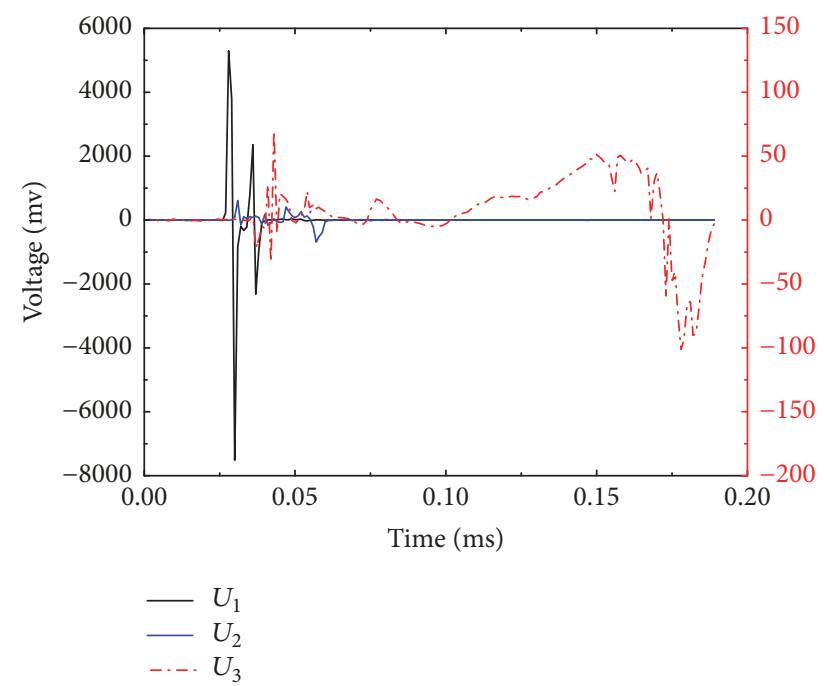

(a)

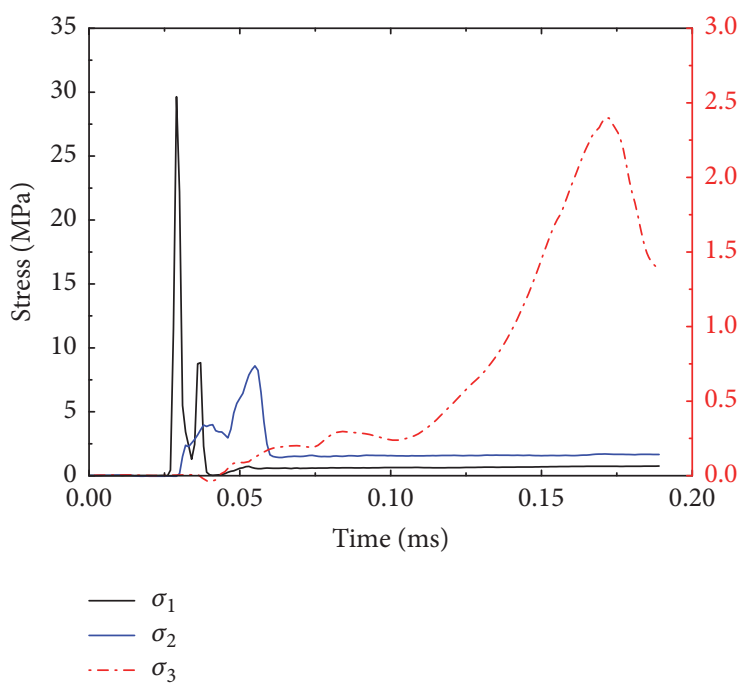

(b)

FIGURE 4: Measurement signal in the sandwich structure: (a) voltage signal; (b) stress signal.

and $\sigma_{3}$ increase, their second peak loads exceed the first peak loads.

The stress wave attenuation in the sandwich structure with ALF core can be divided into two steps. The first step is the multiple transmission and reflection of the stress wave between the interface of steel and the ALF, which is defined as interface effect. The second step is the effect of the porous characteristics of the ALF materials on stress wave attenuation. The attenuation progress of stress wave at the interface can be simplified into a one-dimensional elastic-plastic problem. Owing to the different impedance materials in the sandwich structure, the intensity value of reflected waves and transmitted wave intensity can be expressed as follows:

$$
\begin{aligned}
& \frac{\sigma_{R}}{\sigma_{I}}=\frac{\left(\rho_{2} C_{2}-\rho_{1} C_{1}\right)}{\left(\rho_{2} C_{2}+\rho_{1} C_{1}\right)}, \\
& \frac{\sigma_{T}}{\sigma_{I}}=\frac{2 \rho_{2} C_{2}}{\left(\rho_{2} C_{2}+\rho_{1} C_{1}\right)},
\end{aligned}
$$

where, $\sigma_{I}, \sigma_{R}$, and $\sigma_{T}$, represent the value of incident stress wave, reflected stress wave, and transmitted stress wave, respectively. $\rho_{1} C_{1}$ and $\rho_{2} C_{2}$ represent the wave impedance of the first and second layer material, respectively. In general, the wave impedance of steel plate is two orders of magnitude higher than that of the ALF. Therefore, according to (3) and (4), the value of the transmitted stress wave at the interface between the front sheet and the ALF core will be very small, whereas the value of the reflected wave will be large. Thus, "double-peak" phenomenon appears in the stress wave curve of $\sigma_{1}$ in Figure 4(b). The value of stress wave is reduced from 29.64 to $8.58 \mathrm{MPa}$ because of the influence of interface effect, and the attenuation coefficient is $71.1 \%$. The value of stress wave is reduced from 8.58 to $2.41 \mathrm{MPa}$ because of the influence of the porous characteristics of the ALF, and the attenuation coefficient is $20.8 \%$. The interface effect is the crucial factor in the attenuation of stress waves in the sandwich structure.

The equivalent proportional distance method is generally used to express the peak overpressure of the shock wave. The equivalent proportional distance is defined as shown in (5), where $R$ is the distance between the measuring and the detonating points and $W$ is the mass of equivalent TNT explosive.

$$
\bar{r}=\frac{R}{W^{1 / 3}} .
$$

Henrych and Major [36] studied the peak overpressure in the air and proposed the following empirical prediction formula:

$$
\begin{aligned}
& \Delta P_{1} \\
& = \begin{cases}\frac{1.379}{\bar{r}}+\frac{0.543}{\bar{r}^{2}}-\frac{0.035}{\bar{r}^{3}}+\frac{0.0006}{\bar{r}^{4}} & (0.05 \leq \bar{r} \leq 0.3) \\
\frac{0.607}{\bar{r}}-\frac{0.032}{\bar{r}^{2}}+\frac{0.209}{\bar{r}^{3}} & (0.3 \leq \bar{r} \leq 1) \\
\frac{0.065}{\bar{r}}+\frac{0.397}{\bar{r}^{2}}+\frac{0.322}{\bar{r}^{3}} & (1 \leq \bar{r} \leq 10) .\end{cases}
\end{aligned}
$$

The regular reflected pressure of the air shock wave in the rigid wall is shown in (7), where $\gamma$ is the multiexponent of air and $P_{0}$ is the initial air pressure, as follows:

$$
\Delta P_{2}=2 \Delta P_{1}+\frac{(\gamma+1) \Delta P_{1}^{2}}{\left[(\gamma-1) \Delta P_{1}+2 \gamma P_{0}\right]} .
$$

When the mass of TNT explosives is $500 \mathrm{~g}$, the detonation height is $320 \mathrm{~mm}, \gamma$ is 1.4 , and $P_{0}$ is $0.1 \mathrm{MPa}$, the equivalent proportional distance can be calculated as $0.40 \mathrm{~m} \cdot \mathrm{kg}^{-1 / 3}$, and the incident overpressure is $4.58 \mathrm{MPa}$. According to the above equation, the reflected overpressure is $33.46 \mathrm{MPa}$. The peak load of $\sigma_{1}$ is close to the theoretical value because the mild steel structure can be approximately seen as rigid. However, 

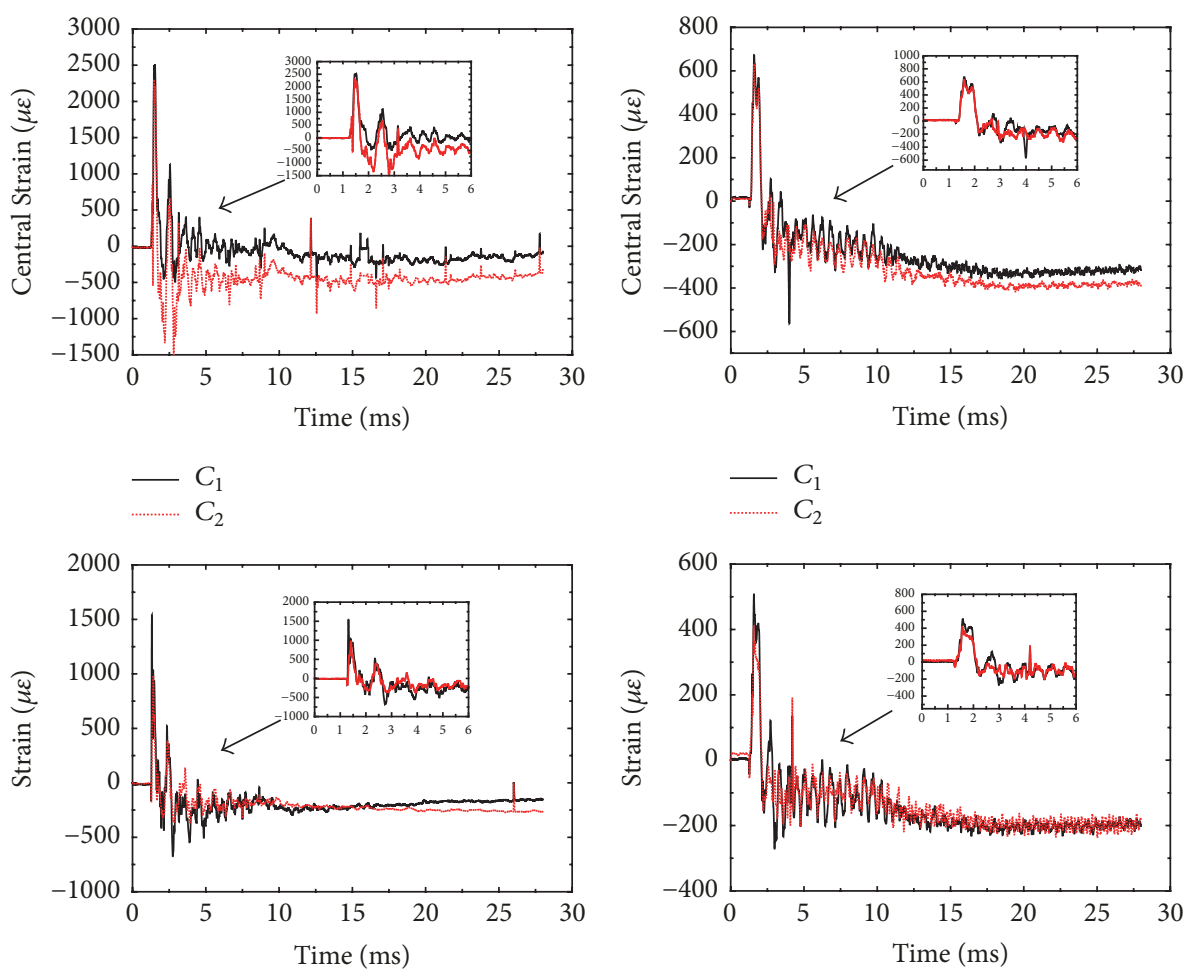

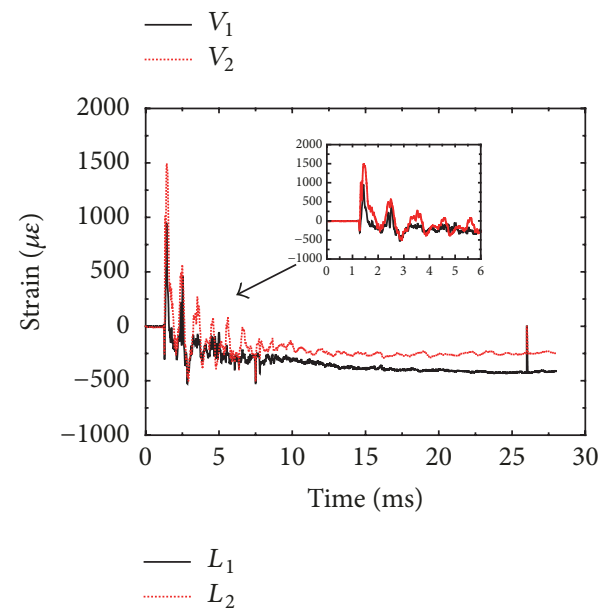

(a)

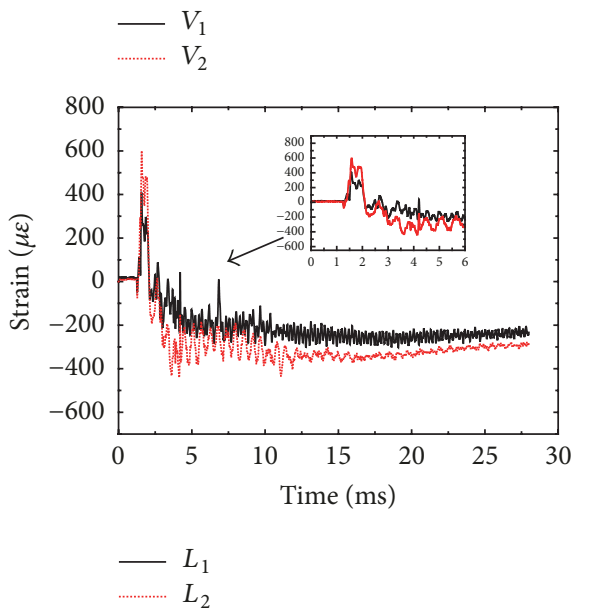

(b)

FIGURE 5: Strain time history curves of (a) mild steel structure and (b) sandwich structure.

the measured peak load of $\sigma_{1}$ in the sandwich structure is $29.64 \mathrm{MPa}$, which is slightly less than the theoretical pressure. The fluid-solid coupling effect caused the reduction of reflected pressure because of the compressive deformation experienced by the ALF core under blast loading [30]. The experimental and theoretical data are basically consistent and indicate that the test results of this experiment are credible.

3.3. Strain Characteristics of Back Sheets in Mild Steel and Sandwich Structures. The strain time history curve of back sheet shown in Figure 5 illustrates the protective results of mild steel and sandwich structures under blast loading. In Figure $5, C_{1}$ and $C_{2}$ are the results of back sheet center at $0^{\circ}$ and $90^{\circ}$ orientations, respectively. $V_{1}$ and $V_{2}$ are the results of rectangular strain rosette at the back sheet $V$ direction measurement point which is $50 \mathrm{~mm}$ away from center point, whereas $L_{1}$ and $L_{2}$ represent the results of rectangular strain rosette at the back sheet $L$ direction measurement point which is also $50 \mathrm{~mm}$ away from center point.

Figure 5(a) represents the strain time history curves of back sheet in the mild steel structure. The law of strain change is consistent at the three measured positions. The peak value of strain is largest at the first cycle and then gradually decreases. Finally, a negative offset is observed, indicating that residual strain occurred in the back sheet. Figure 5(b) depicts the strain time history curves of the back sheet in the 
TABLE 1: Peak value of strain in mild steel and sandwich structure.

\begin{tabular}{lcccccc}
\hline Structures & $C_{1}(\mu \varepsilon)$ & $C_{2}(\mu \varepsilon)$ & $V_{1}(\mu \varepsilon)$ & $V_{2}(\mu \varepsilon)$ & $L_{1}(\mu \varepsilon)$ & $L_{2}(\mu \varepsilon)$ \\
\hline Mild steel & 2513 & 2284 & 1540 & 993 & 943 & 1490 \\
Sandwich & 672 & 634 & 507 & 411 & 408 & 596 \\
\hline
\end{tabular}

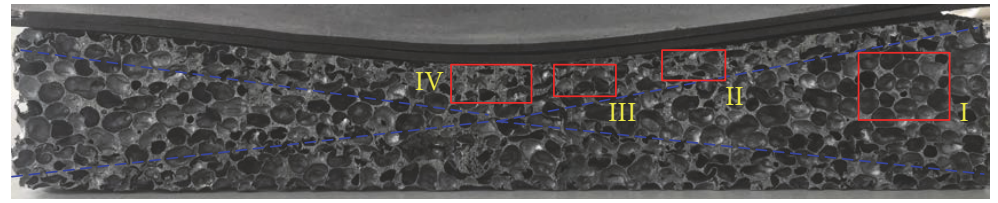

(a)

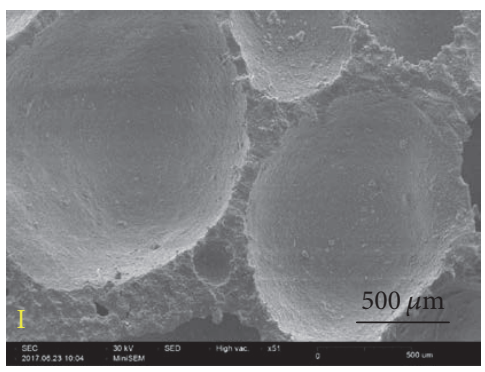

(b)

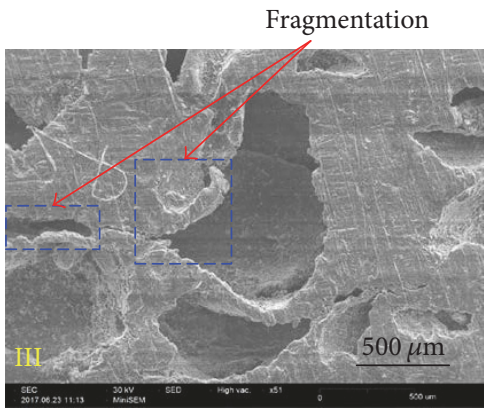

(d)

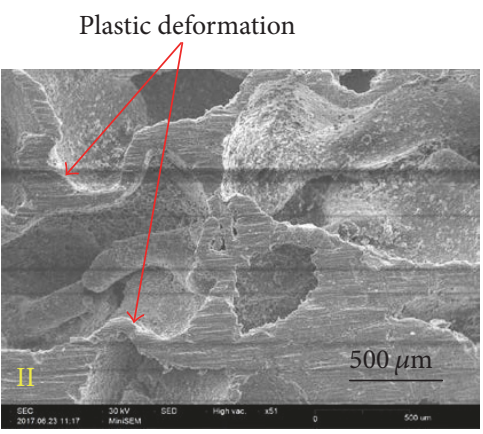

(c)

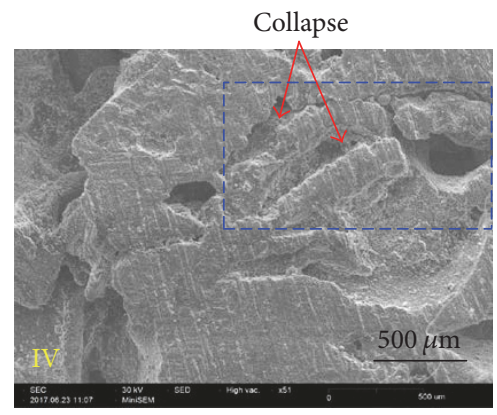

(e)

FIGURE 6: (a) Destruction image of aluminum foam under blast loading, (b)-(e) SEM images in different regions.

sandwich structure. It can be seen that the strain curves are similar to that of mild steel structure, but the peak values of strain are much smaller.

The peak value of the back sheet strain is shown in Table 1. The peak value of the strain at center position $\left(C_{1} / C_{2}\right)$ is much higher than that at other positions $\left(V_{1} / V_{2}, L_{1} / L_{2}\right)$. The peak values of the strain in the $V$ and $L$ directions are similar to the symmetrical position $\left(V_{1} / L_{2}, L_{1} / V_{2}\right)$. The strain values indicate that the impact position of shock wave is basically located at the center of the sandwich and mild steel structures. In the mild steel structure, the center strains $C_{1}$ and $C_{2}$ are 2513 and $2284 \mu \varepsilon$, respectively. In the sandwich structure, the center strains $C_{1}$ and $C_{2}$ are 672 and $634 \mu \varepsilon$, respectively. Their strains in the sandwich structure are much less than those of the mild steel plate.

3.4. Deformation Mechanism of Aluminum Foam Core. Figure 6 depicts the typical damage profile of the sandwich structure and shows that serious deformation occurred in the sandwich structure. The SEM image shows the detailed deformation of the cell wall.

The cover plate and the front sheet show large plastic deformation and the apparent overall " $X$ " crushing band produced in the ALF core caused by the free edge effect from the sides. The deformation of ALF can be divided into four regions. In Region I, the unaffected zone, an elastic deformation occurred in the cell wall. In Region II, an apparent plastic deformation occurred in the cell wall. In Region III, fragmentation occurred in the cell wall, indicating that the ALF was destroyed. In Region IV, the cell wall was collapsed.

Actually, multiple reflections occurred in the interface between the cell wall and air as a result of the porous structure of aluminum foam. The wave propagating became more and more dispersed due to the multiply wave interaction in the aluminum foam. So the pressure perpendicular to 
TABLE 2: Stress wave in the sandwich structure with different ALF relative densities.

\begin{tabular}{lcccccc}
\hline Relative density & $\sigma_{1}(\mathrm{MPa})$ & $\sigma_{2}(\mathrm{MPa})$ & $\sigma_{3}(\mathrm{MPa})$ & $\beta_{1}$ & $\beta_{2}$ \\
\hline 0.116 & 29.32 & 5.37 & 1.13 & 0.817 & 0.145 & 0.961 \\
0.125 & 29.73 & 5.92 & 1.45 & 0.801 & 0.150 \\
0.143 & 29.34 & 6.61 & 1.69 & 0.775 & 0.167 \\
0.154 & 29.64 & 7.36 & 1.88 & 0.752 & 0.185 \\
0.162 & 29.78 & 7.96 & 2.05 & 0.733 & 0.942 \\
0.206 & 29.64 & 8.58 & 2.41 & 0.711 & 0.937 \\
\hline
\end{tabular}

TABLE 3: Stress wave in the sandwich structure with different ALF thicknesses.

\begin{tabular}{lcccccc}
\hline Thickness $(\mathrm{mm})$ & $\sigma_{1}(\mathrm{MPa})$ & $\sigma_{2}(\mathrm{MPa})$ & $\sigma_{3}(\mathrm{MPa})$ & $\beta_{1}$ & $\beta_{2}$ & 0.165 \\
438 & 30.26 & 8.72 & 3.73 & 0.712 & 0.877 \\
43 & 29.54 & 8.61 & 2.96 & 0.709 & 0.191 & 0.900 \\
48 & 29.64 & 8.58 & 2.41 & 0.711 & 0.208 \\
53 & 29.63 & 8.60 & 2.33 & 0.710 & 0.212 & 0.919 \\
58 & 29.65 & 8.53 & 2.20 & 0.712 & 0.213 \\
\hline
\end{tabular}

the aluminum foam core was attenuated since the dispersive effect. In addition, the plastic deformation and cracks growth of the cell wall are obvious in Figure 6, and the energy was dissipated mainly by the damage of cell wall. So the apparent overall " $\mathrm{X}$ " crushing band could be considered as another important reason for the stress wave attenuation.

\section{Effect of Different ALF Parameters on the Stress Wave Attenuation}

4.1. Effect of ALF Relative Density on the Stress Wave Attenuation. Some experiments were conducted to study the effect of the relative density of ALF on stress wave attenuation. The relative density of ALF ranges from $11.6 \%$ to $20.6 \%$. Stress waves between different interfaces $\left(\sigma_{1} / \sigma_{2} / \sigma_{3}\right)$ were measured, and the results are shown in Table 2 .

Although the relative density of ALF is different, the value of $\sigma_{1}$ is almost constant. Increasing the relative density of the ALF results in increase of the values of $\sigma_{2}$ and $\sigma_{3}$. When the relative density of ALF increases, the wave impedance increases, and according to (4), we can predict that the transmitted stress will increase. The attenuation coefficient could then be calculated according to (2). $\beta_{1}$ represents the attenuation factor caused by interface effect, $\beta_{2}$ represents the attenuation factor caused by the porous characteristic of ALF, and $\beta$ represents the attenuation factor of the whole sandwich structure. The effect of the relative density of ALF on the attenuation factor is shown in Figure 7.

Figure 7 depicts the effect of ALF relative density on the wave attenuation factor. The attenuation factor trends of ALF and sandwich structure vary inversely with the relative density of the ALF. As the relative density of ALF increases, its attenuation coefficient tends to increase. However, the attenuation coefficient of sandwich structure tends to decrease. These results are similar to the research of Liu et al. [35]. When the relative density is small, the stress transmitted to the ALF at the interface is weak, so the total attenuation coefficient of the sandwich panel is clearly

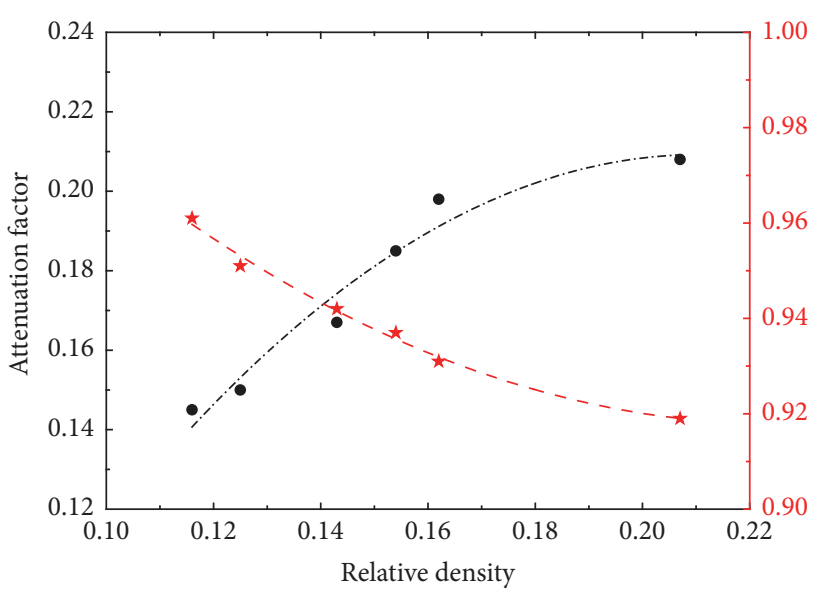

- Experimental data of ALF

$\star$ Experimental data of Sandwich

FIGURE 7: Influence of ALF relative density.

enhanced. Moreover, these results explain the fact that the interface effect is the main reason for the attenuation of stress wave in the sandwich structure.

4.2. Effect of ALF Thickness on the Stress Wave Attenuation. Some experiments were also conducted to study the effect of the thickness of ALF on stress wave attenuation. The thicknesses of ALF ranges from $38 \mathrm{~mm}$ to $53 \mathrm{~mm}$, while the relative densities of ALF are all in the scope of $19.8 \%-20.6 \%$. Stress waves between different interfaces $\left(\sigma_{1} / \sigma_{2} / \sigma_{3}\right)$ were measured, and the results are shown in Table 3. Although the thickness of ALF is different, the values of $\sigma_{2}$ in every experiment are almost constant. It means that increasing or decreasing the thickness of the ALF does not affect the stress at the interface between the front sheet and the ALF. However, increasing the ALF thickness results in decrease of the value of $\sigma_{3}$. 


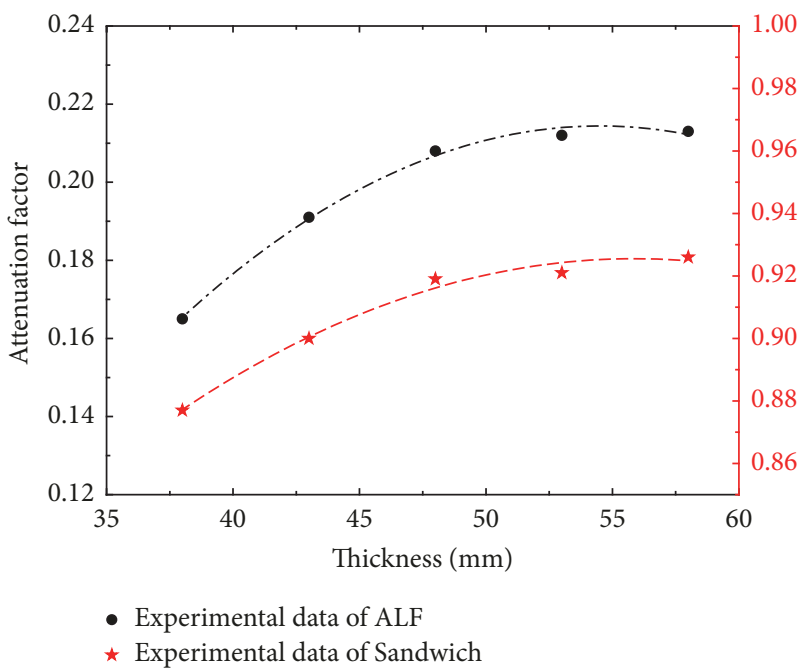

FIGURE 8: Influence of ALF thickness.

Figure 8 depicts the effect of the ALF thickness on the attenuation factor. It can be seen that the attenuation factor trends of ALF and sandwich structure are similar. As the thickness increases, the attenuation coefficients of ALF and sandwich structure tend to increase. However, when the thickness of ALF exceeds $48 \mathrm{~mm}$, the growth of attenuation factor is not obvious.

\section{Conclusions}

Some experiments were conducted in this study to investigate the attenuation of the stress wave in the sandwich structure with ALF under blast loading. The PVDF transducers with high frequency response were used to test the stress waves between different interfaces, whereas the high-precision strain gauges were selected to measure the strain of the back sheet. The experimental results show that the ALF sandwich structure is extremely helpful in reducing the peak load of the stress wave compared with the mild steel structure without ALF core. The attenuation coefficient could exceed $90 \%$, whereas the attenuation coefficient of the mild steel structure is only $11.3 \%$. By measuring the strain of back sheet in different structures, the strains in the sandwich structure are found to be much less than the mild steel plate. By measuring the stress between the front sheet and the ALF, the interface effect is determined to be the main factor of the attenuation of the stress wave in the sandwich structure. By measuring the stress of sandwich structure with different ALF relative densities, increasing the relative density is found to increase the attenuation capability of the ALF but decrease the attenuation capability of the sandwich structure. Experiments on the sandwich structure with different aluminum foam thickness indicate that increasing the thickness results in increased wave attenuation capability of the aluminum foam and the sandwich structure. The apparent overall " $\mathrm{X}$ " crushing band was produced in the aluminum foam under blast loading, and the phenomenon could be considered as an important reason for the stress wave attenuation.

\section{Conflicts of Interest}

The authors declare that they have no conflicts of interest.

\section{References}

[1] H. Qingxian, Q. Sawei, and H. Yuebo, "Development on preparation technology of aluminum foam sandwich panels," Rare Metal Materials and Engineering, vol. 44, no. 3, pp. 548-552, 2015.

[2] H. Wang, X.-Y. Zhou, B. Long, J. Yang, and H.-Z. Liu, “Thermal properties of closed-cell aluminum foams prepared by melt foaming technology," Transactions of Nonferrous Metals Society of China, vol. 26, no. 12, pp. 3147-3153, 2016.

[3] S. Birla, D. P. Mondal, S. Das, D. K. Kashyap, and V. A. N. Ch, "Effect of cenosphere content on the compressive deformation behaviour of aluminum-cenosphere hybrid foam," Materials Science and Engineering: A Structural Materials: Properties, Microstructure and Processing, vol. 685, pp. 213-226, 2017.

[4] S. Birla, D. P. Mondal, S. Das, A. Khare, and J. P. Singh, "Effect of cenosphere particle size and relative density on the compressive deformation behavior of aluminum-cenosphere hybrid foam," Materials and Corrosion, vol. 117, pp. 168-177, 2017.

[5] A. Aldoshan and S. Khanna, "Effect of relative density on the dynamic compressive behavior of carbon nanotube reinforced aluminum foam," Materials Science and Engineering: A Structural Materials: Properties, Microstructure and Processing, vol. 689, pp. 17-24, 2017.

[6] Y. Hangai, T. Morita, and T. Utsunomiya, "Functionally graded aluminum foam consisting of dissimilar aluminum alloys fabricated by sintering and dissolution process," Materials Science and Engineering: A Structural Materials: Properties, Microstructure and Processing, vol. 696, pp. 544-551, 2017.

[7] R. Matsumoto, S. Kanatani, and H. Utsunomiya, "Filling of surface pores of aluminum foam with polyamide by selective laser melting for improvement in mechanical properties," Journal of Materials Processing Technology, vol. 237, pp. 402-408, 2016.

[8] P. Wang, S. Xu, Z. Li et al., "Experimental investigation on the strain-rate effect and inertia effect of closed-cell aluminum foam subjected to dynamic loading," Materials Science and Engineering: A Structural Materials: Properties, Microstructure and Processing, vol. 620, pp. 253-261, 2014.

[9] J. Shen, G. Lu, and D. Ruan, "Compressive behaviour of closedcell aluminium foams at high strain rates," Composites Part B: Engineering, vol. 41, no. 8, pp. 678-685, 2010.

[10] S. Wang, Y. Ding, C. Wang, Z. Zheng, and J. Yu, "Dynamic material parameters of closed-cell foams under high-velocity impact," International Journal of Impact Engineering, vol. 99, pp. 111-121, 2017.

[11] Y. Xia, C. Wu, Z.-X. Liu, and Y. Yuan, "Protective effect of graded density aluminium foam on RC slab under blast loading-An experimental study," Construction and Building Materials, vol. 111, pp. 209-222, 2016.

[12] N. Movahedi and S. M. H. Mirbagheri, "Comparison of the energy absorption of closed-cell aluminum foam produced by various foaming agents," International Journal of Strength of Materials, vol. 48, no. 3, pp. 444-449, 2016.

[13] J. Park and H.-J. Choi, "Experiments and numerical analyses of HB400 and aluminum foam sandwich structure under landmine explosion," Composite Structures, vol. 134, pp. 726739, 2015. 
[14] S. Li, X. Li, Z. Wang, G. Wu, G. Lu, and L. Zhao, "Finite element analysis of sandwich panels with stepwise graded aluminum honeycomb cores under blast loading," Composites Part A: Applied Science and Manufacturing, vol. 80, pp. 1-12, 2016.

[15] X. Qiu, V. S. Deshpande, and N. A. Fleck, "Dynamic response of a clamped circular sandwich plate subject to shock loading," Journal of Applied Mechanics, vol. 71, no. 5, pp. 637-645, 2004.

[16] V. S. Deshpande and N. A. Fleck, "One-dimensional response of sandwich plates to underwater shock loading," Journal of the Mechanics and Physics of Solids, vol. 53, no. 11, pp. 2347-2383, 2005.

[17] F. Zhu, Z. Wang, G. Lu, and G. Nurick, "Some theoretical considerations on the dynamic response of sandwich structures under impulsive loading," International Journal of Impact Engineering, vol. 37, no. 6, pp. 625-637, 2010.

[18] G. S. Langdon, D. Karagiozova, M. D. Theobald, G. N. Nurick, G. Lu, and R. P. Merrett, "Fracture of aluminium foam core sacrificial cladding subjected to air-blast loading," International Journal of Impact Engineering, vol. 37, no. 6, pp. 638-651, 2010.

[19] L. Jing, Z. Wang, and L. Zhao, "Dynamic response of cylindrical sandwich shells with metallic foam cores under blast loading-numerical simulations," Composite Structures, vol. 99, pp. 213-223, 2013.

[20] L. Jing, Z. Wang, V. P. W. Shim, and L. Zhao, "An experimental study of the dynamic response of cylindrical sandwich shells with metallic foam cores subjected to blast loading," International Journal of Impact Engineering, vol. 71, pp. 60-72, 2014.

[21] J. Shen, G. Lu, Z. Wang, and L. Zhao, "Experiments on curved sandwich panels under blast loading," International Journal of Impact Engineering, vol. 37, no. 9, pp. 960-970, 2010.

[22] W. Li, G. Huang, Y. Bai, Y. Dong, and S. Feng, "Dynamic response of spherical sandwich shells with metallic foam core under external air blast loading - Numerical simulation," Composite Structures, vol. 116, no. 1, pp. 612-625, 2014.

[23] X. Liu, X. Tian, T. J. Lu, D. Zhou, and B. Liang, "Blast resistance of sandwich-walled hollow cylinders with graded metallic foam cores," Composite Structures, vol. 94, no. 8, pp. 2485-2493, 2012.

[24] X. R. Liu, X. G. Tian, T. J. Lu, and B. Liang, "Sandwich plates with functionally graded metallic foam cores subjected to air blast loading," International Journal of Mechanical Sciences, vol. 84, pp. 61-72, 2014.

[25] P. J. Tan, S. R. Reid, J. J. Harrigan, Z. Zou, and S. Li, “Dynamic compressive strength properties of aluminium foams. Part II- "shock" theory and comparison with experimental data and numerical models," Journal of the Mechanics and Physics of Solids, vol. 53, no. 10, pp. 2206-2230, 2005.

[26] D. Karagiozova, G. S. Langdon, and G. N. Nurick, "Blast attenuation in Cymat foam core sacrificial claddings," International Journal of Mechanical Sciences, vol. 52, no. 5, pp. 758-776, 2010.

[27] D. Karagiozova and M. Alves, "Compaction of a double-layered metal foam block impacting a rigid wall," International Journal of Solids and Structures, vol. 51, no. 13, pp. 2424-2438, 2014.

[28] D. Karagiozova and M. Alves, "Propagation of compaction waves in cellular materials with continuously varying density," International Journal of Solids and Structures, vol. 71, pp. 323337, 2015.

[29] D. Karagiozova, G. S. Langdon, and G. N. Nurick, "Propagation of compaction waves in metal foams exhibiting strain hardening," International Journal of Solids and Structures, vol. 49, no. 19-20, pp. 2763-2777, 2012.
[30] M. Aleyaasin, J. J. Harrigan, and S. R. Reid, "Air-blast response of cellular material with a face plate: An analytical-numerical approach," International Journal of Mechanical Sciences, vol. 91, pp. 64-70, 2015.

[31] M. Turkyilmazoglu, "Air blast response of compaction foam having a deformable front face panel incorporating fluid structure interactions," International Journal of Mechanical Sciences, vol. 105, pp. 340-347, 2016.

[32] M. Liang, Z. Li, F. Lu, and X. Li, "Theoretical and numerical investigation of blast responses of continuous-density graded cellular materials," Composite Structures, vol. 164, pp. 170-179, 2017.

[33] M. D. Goel, P. Altenhofer, V. A. Matsagar, A. K. Gupta, C. Mundt, and S. Marburg, "Interaction of a shock wave with a closed cell aluminum metal foam," Combustion, Explosion and Shock Waves, vol. 51, no. 3, pp. 373-380, 2015.

[34] X. Liang, H. Luo, Y. Mu, L. Wu, and H. Lin, "Experimental study on stress attenuation in aluminum foam core sandwich panels in high-velocity impact," Materials Letters, vol. 203, pp. 100-102, 2017.

[35] H. Liu, Z. K. Cao, G. C. Yao, H. J. Luo, and G. Y. Zu, "Performance of aluminum foam-steel panel sandwich composites subjected to blast loading," Materials and Corrosion, vol. 47, pp. 483-488, 2013.

[36] J. Henrych and R. Major, The Dynamics of Explosion and Its Use, Elsevier, Amsterdam, 1979. 


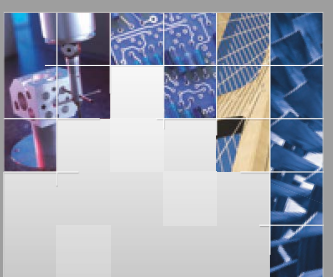

\section{Enfincering}
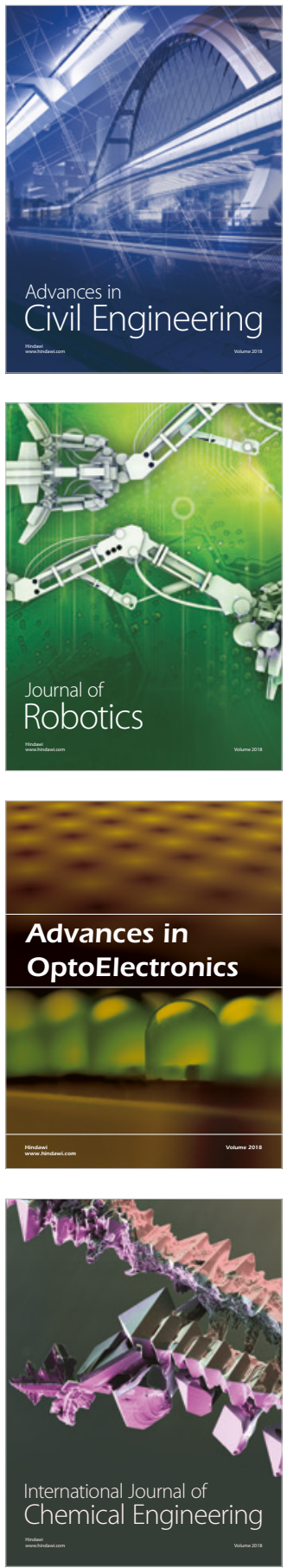

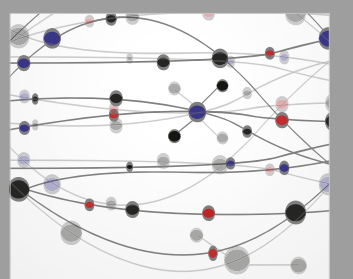

\section{Rotating \\ Machinery}

The Scientific World Journal

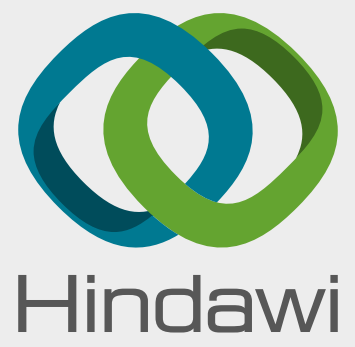

Submit your manuscripts at

www.hindawi.com
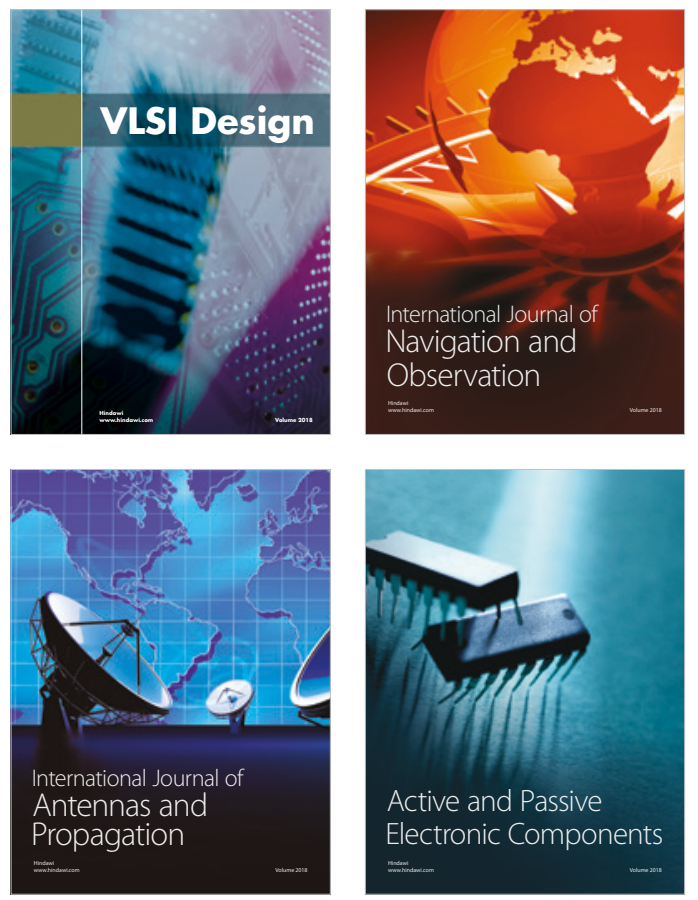
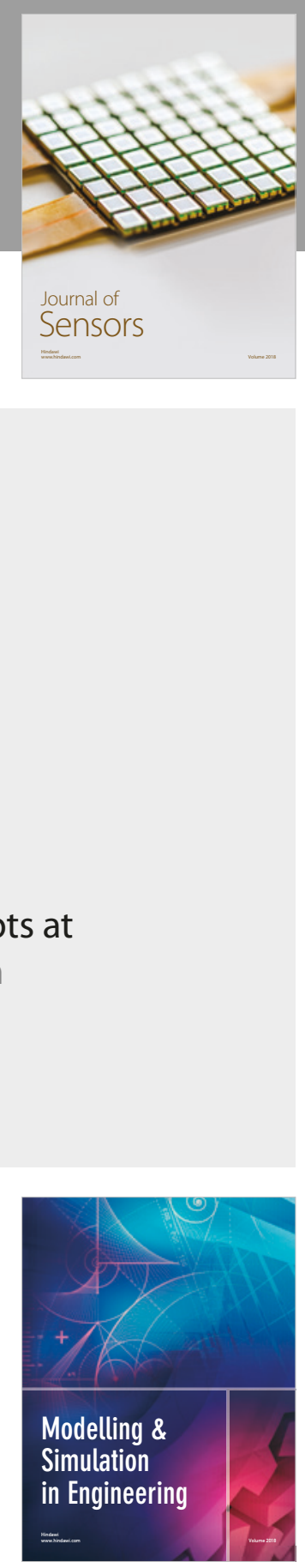

\section{Advances \\ Multimedia}
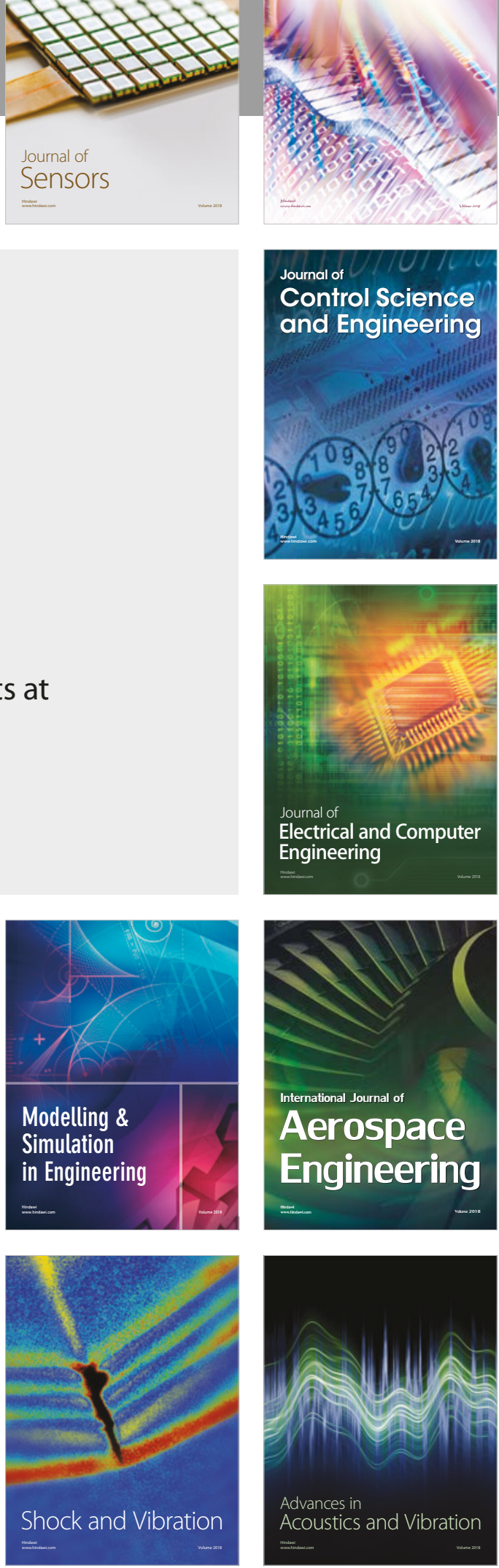